\begin{tabular}{|c|c|c|}
\hline & Int.J.Curr.Microbiol.App.Sci (2016) 5(8): $429-435$ & \\
\hline & International Journal of Current Microbiology and Applied Sciences & \\
\hline & ISSN: 2319-7706 Volume 5 Number 8 (2016) pp. 429-435 & \\
\hline $\begin{array}{l}\text { EXCELLENT } \\
\text { PUBLISHERS }\end{array}$ & & www ijomas,com \\
\hline
\end{tabular}

Original Research Article

http://dx.doi.org/10.20546/ijcmas.2016.508.046

\title{
Prevalence of Intestinal Parasitic Pathogens in Stools from Medical Speciality Units of Tertiary Rural Teaching Hospital, Tamilnadu, India
}

\author{
R. Saraswathi ${ }^{1}{ }^{*}$, J. Lalithambigai ${ }^{1}$, G. Vazhavandal $^{1}$, A. Uma ${ }^{1}$, \\ N. Prabhusaran ${ }^{1}$ and A. Velayutharaj ${ }^{2}$ \\ ${ }^{1}$ Department of Microbiology, Chennai Medical College Hospital and Research Centre \\ (SRM Group), Tiruchirapalli, India \\ ${ }^{2}$ Department of Biochemistry, Chennai Medical College Hospital and Research Centre \\ (SRM Group), Tiruchirapalli, India \\ *Corresponding author
}

\begin{abstract}
A B S T R A C T
\section{Keywords}

Intestinal

parasites,

Giardia,

Entamoeba, prevalence.

\section{Article Info}

Accepted:

21 July 2016

Available Online:

10 August 2016

In the present investigation, a cross sectional laboratory survey of intestinal parasitic infections in relation to samples requested to Microbiology laboratory. The main objective of this study is to determine the prevalence of intestinal parasitic infections in the stool samples at tertiary care teaching hospital, Tiruchirapalli, Tamilnadu. A total of 726 stool samples were included and examined in this study. The color, consistency and nature of stool samples were recorded. Further all the samples were subjected for examining the presence of parasitic worms by wet mount microscopy and confirmed by concentration procedures. As a result in stool samples, yellow color dominated followed by brown, black etc. the stool consistency was observed and maximum were recorded as solid. The maximum numbers of stool samples were enrolled from department of General Medicine followed by casualty and psychiatry. After thorough microscopic examinations, the common parasites identified are Giardia lamblia (3.5\%), Entamoeba histolytica (2.5\%), Hookworms (1\%) and Ascaris lumbricoides $(0.7 \%)$. The present study has demonstrated the presence of various intestinal parasitic pathogens in Tiruchirapalli district of India.
\end{abstract}

\section{Introduction}

Parasitic infections are a major public health problem worldwide; particularly in the developing countries like India. The prevalence of the intestinal parasitic infections varies from one region to another; person to person and seasonable variations (Latha et al., 2010). In India, malnutrition, unhygienic conditions, the improper disposal of sewage and the non-availability of potable water supplies in the rural and the urban areas are responsible for the high rate of intestinal parasitic infections (Parameshwarappa et al., 2012). These infections are major causes of morbidity and mortality throughout the world and particularly in developing countries where mortality rate due to infectious diarrhoea could be as high as 56\% (Guerrant et al., 
2005; Samie et al., 2009). Recent estimations suggested that the mortality is close to 2.5 million (Saeed et al., 2015). Children and young adults are the most affected, particularly in regions with limited resources and where hygienic measures are not strictly followed (Samie et al., 2009).

The number of people who are affected by Giardia lamblia, whipworm, roundworm and hookworm in the developing world has been estimated to be 200, 500, 700 and 800 million respectively (Parameshwarappa et al., 2012; Sethi et al., 2000). The conventional methods which are used for the detection of intestinal parasites from stool include the direct wet mount and the iodine mount. The conventional methods lack sensitivity in the detection of parasites in the stool specimens by observing artifacts. The microscopic detection of parasites in the fecal specimens is enhanced by the use of concentration procedures.

Various concentration techniques were developed like simple salt floatation, Zinc sulphate centrifugal floatation and modified formal-ether concentration are employed for the diagnosis and epidemiological surveillance of parasitic infections in humans. These techniques increase the detection of the helminthic eggs, larvae and the protozoan cysts. Certain techniques like formal-ether concentration have the advantages of less alteration to the organisms and an increased recovery of the Schistosoma spp. and operculated eggs (Sethi et al., 2000). In view of the increasing polyparasitism in the developing countries, there is a need of sensitive diagnostic tools that are simple to apply and to concurrently detect different intestinal parasitic species in the same stool sample.

There is no sufficient data related to epidemiology on the distribution and prevalence of intestinal parasites in symptomatic patients (Ganesh et al., 2013). Although several studies on parasitic infections have been carried out in different parts all over India, there are no reports of prevalence of parasitic infections from this study district. The survey on prevalence of various parasites is a prerequisite to develop appropriate control strategies (Mahesh et al., 2011). The microbiology laboratory of our hospital is receiving an increased number of requests for the analysis of stool specimens for ova and parasites. This trend prompted us to evaluate the distribution of intestinal parasites microscopically diagnosed by our laboratory over a period of 8 months. Further the authors believe that this study is important as they provide basic data for the control of parasitic infections in future.

\section{Materials and Methods}

\section{Study population}

A prospective study was carried out in the department of Microbiology for a period of eight months (October 2014 to May 2015). The study population included patients of both sexes and all age groups including children, pregnant women and elderly individuals attending the outpatient and inpatient departments of a medical college hospital in Tiruchirapalli, India. Seven hundred and twenty six (726) stool samples with complaints suggestive of parasitic infections including preventive health care checkups, coming to our tertiary care teaching hospital for whom stool examination for parasites was advised by clinicians were included in this study. Patients who had taken anti-parasitic drug during the last two months were also excluded from the study. Ethical clearance was obtained from the institutional ethics committee and informed consent was obtained in the sample collection centre itself. 


\section{Sample collection}

Stool samples were collected in accordance with WHO guidelines on the collection of fecal samples (WHO, 1991). Fresh morning stool samples were collected in a wide mouthed clean and sterile container. Approximately 5 grams of solid stool or about $10 \mathrm{ml}$ of liquid stool was collected (Nkrumah and Nguah, 2011). Demographic data regarding age and sex was also collected.

\section{Methods of stool examination}

All the samples were processed immediately without delay within half an hour. Macroscopic examination was done to identify color, consistency and blood stain. Unstained saline wet mount and iodine preparation was done to detect protozoal trophozoites and helminthic eggs or larvae. The formal-ether concentration technique was also performed for the samples that showed very low count of parasites in microscope (Allen and Ridley, 1970).

\section{Results and Discussion}

A total of 726 stool samples were examined out of which $55(7.6 \%)$ revealed the presence of parasites. Previous study highlighted with $10.7 \%$ (Randhir et al., 2014). Among the age groups, 41 to 50 years of age were enrolled maximum (26.6\%) followed by 31 to 40 and 51 to 60 with $20.2 \%$ and $19.9 \%$ respectively. Of the 55 positive cases, the maximum infection age group is 51 to 60 (20\%) followed by 31 to 40,41 to 50 and 1 to 10 with the infection rate of $18.2 \%, 14.5 \%$ and $14.5 \%$ respectively.

The descriptive details of various age groups, its distribution and infectious data were depicted in table 1. Among the subjects included, the maximum stool samples were referred from preventive health care checkups (69.5\%). Among the clinical departments, pediatrics referred maximum $(8.8 \%)$ followed by General Medicine $(6.2 \%)$, surgery $(4 \%)$ etc. the detailed analysis of department wise sample reference was impregnated in figure 1.

Of the 55 positive cases, 49 (89.1\%) were positive by normal saline (wet mount microscopy) and iodine preparation and an additional $6(10.9 \%)$ parasites were detected by formal ether concentration technique. Among these 55 samples, 47 (85.4\%) samples were infected with at least one parasite, $7(12.8 \%)$ were infected with two parasites and $1(1.8 \%)$ were infected with three parasites (Figure 2).

Protozoans formed 55 (7.6\%) of the total parasitic infestations while hook worm infections was seen in 7 (12.7\%) samples. The most common pathogenic intestinal parasite was Giardia lamblia $45.5 \%$ followed by Entamoeba histolytica 32.7\% and Ascaris lumbricoides $9.1 \%$ (Figure 3).

Among the study population, 445 were males and 281 were females. The total number of positive cases was more in male $33 / 55(60 \%)$ as compared to females $22 / 55$ $(40 \%)$. Maximum number of positive cases in males $(27.2 \%)$ were in the age group 51 60 years and in females (27.3\%) were in the 41 - 50 years (Table 1). In the case of polyparasitic observation, existence of two and three different parasites in the same sample was observed most commonly with Giardia lamblia and Entamoeba histolytica $(37.5 \%)$ followed by G. lamblia and hookworm (25\%); E. histolytica and hook worm (12.5\%) and G. lamblia and Ascaris lumbricoides (12.5\%). Among the three parasitic infections, only one sample supported with the combinations of $E$. histolytica, G. lamblia and hookworm (12.5\%) (Figure 4). 
Stool examination for parasitic ova, cysts, trophozoites and larvae remains the gold standard for laboratory diagnosis for intestinal parasitic infections (WHO, 1991). Lack of knowledge of prevalence of parasites in a particular geographic area may lead to misdiagnosis of intestinal parasitic infections as appendicitis and other inflammatory bowel diseases (Bandy et al., 1988). Studies outside India have reported a parasitic prevalence rate of 25 to $70 \%$ (Srihari et al., 2011). Prevalence rate of the parasitic infections was low $(7.6 \%)$ in our study population as compared to other studies (Bandy et al., 1988; Srihari et al., 2011; Randhir et al., 2014; Yam et al., 2012). In the absence of substantial community based study on the lifestyle of the rural population, this low rate of such intestinal infections cannot be explained.

None of the individuals had any apparent ill effects because of the parasites. In this study, although there was no demonstrable effect on the health of the subjects in the form of symptomatic disease, the observation that subjects in the same environment can excrete parasites with high or low frequency indicates that host-related factors probably determine parasite excretion rates (Kang et al., 1998). Acute infectious diarrhoea is likely to be the result of an alteration of the environment of the gut associated with presence of a pathogenic organism and a better understanding of gut ecology may help in devising optimum methods of control.

These parasitic infections have been commonly reported from different parts of India. The difference in prevalence can also be due to different selection of cases with different immune status and difference in method of stool examination. The patients might acquire multiple parasitic infections because of poor sanitary conditions (Manish et al., 2013).

Table.1 Age wise distribution of subjects and its infectious data

\begin{tabular}{|c|c|c|c|c|}
\hline $\begin{array}{c}\text { Age group (in } \\
\text { years) }\end{array}$ & \multicolumn{2}{|c|}{$\begin{array}{c}\text { No. of Samples tested } \\
(\mathbf{n - 7 2 6})\end{array}$} & $\begin{array}{c}\text { No. of infected cases } \\
(\mathbf{n = 5 5})\end{array}$ \\
\cline { 2 - 5 } & $\begin{array}{c}\text { Male } \\
(\mathbf{n = 4 4 5 )}\end{array}$ & $\begin{array}{c}\text { Female } \\
(\mathbf{n = 2 8 1})\end{array}$ & $\begin{array}{c}\text { Male } \\
(\mathbf{n = 3 3 )}\end{array}$ & $\begin{array}{c}\text { Female } \\
(\mathbf{n = 2 2})\end{array}$ \\
\hline $\mathbf{1 - \mathbf { 1 0 }}$ & $27(6.1)$ & $25(8.8)$ & $5(15.1)$ & $3(13.6)$ \\
\hline $\mathbf{1 1}-\mathbf{2 0}$ & $13(2.9)$ & $10(3.6)$ & $2(6.1)$ & $3(13.6)$ \\
\hline $\mathbf{2 1}-\mathbf{3 0}$ & $53(11.9)$ & $17(6.1)$ & $4(12.1)$ & $2(9.1)$ \\
\hline $\mathbf{3 1}-\mathbf{4 0}$ & $94(21.2)$ & $53(18.8)$ & $6(18.2)$ & $4(18.3)$ \\
\hline $\mathbf{4 1 - \mathbf { 5 0 }}$ & $107(24.1)$ & $84(29.9)$ & $2(6.1)$ & $6(27.3)$ \\
\hline $\mathbf{5 1}-\mathbf{6 0}$ & $74(16.6)$ & $71(25.4)$ & $9(27.2)$ & $2(9.1)$ \\
\hline $\mathbf{6 1}-\mathbf{7 0}$ & $56(12.5)$ & $18(6.4)$ & $3(9.1)$ & $1(4.5)$ \\
\hline $\mathbf{7 1}-\mathbf{8 0}$ & $21(4.7)$ & $3(1.1)$ & $2(6.1)$ & $1(4.5)$ \\
\hline
\end{tabular}

[Figure in parenthesis denoted percentages] 
Fig.1 Pattern of sample reference form various departments

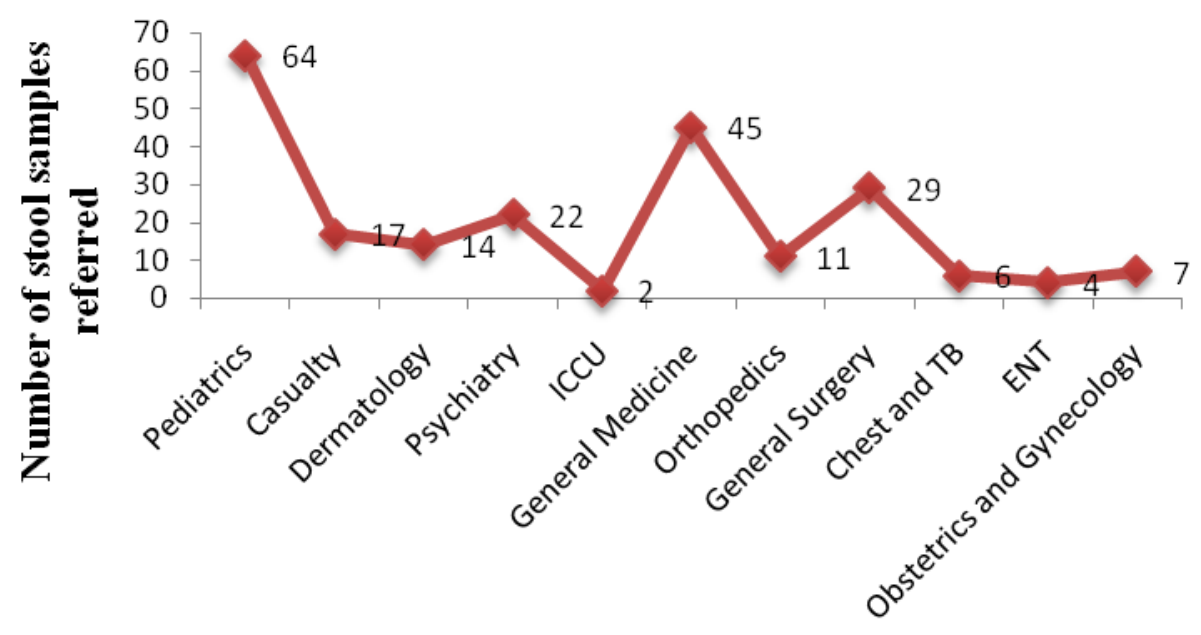

Departments that request for stool microscopy

Fig.2 Mono and polyparasitic infections

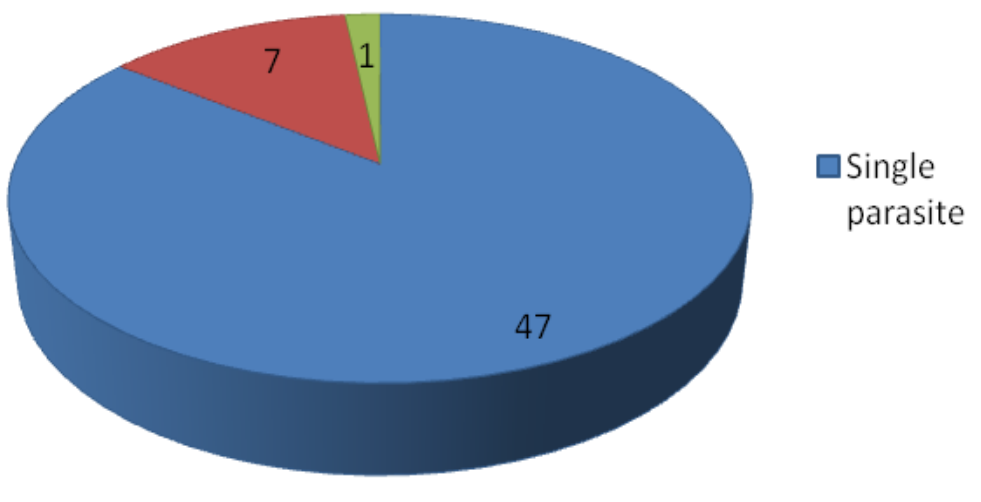

Fig.3 Prevalence of common parasitic pathogens in the samples

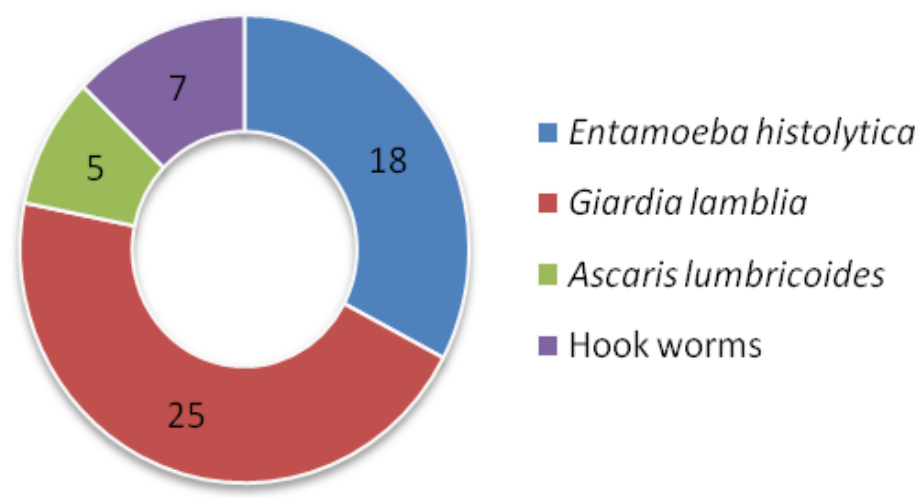


Fig.4 Pattern of parasitic infections

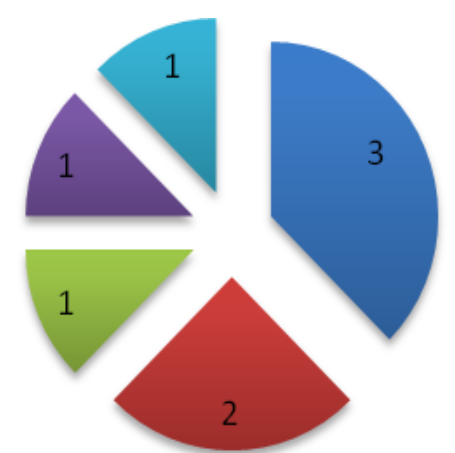

Overall the presence of intestinal parasites suggests that, there could be other potentially pathogenic infections among the patients. Although proportionally the number of males in this study was also higher, the prevalence based on gender suggests males are more likely infected than females. Overcrowding which is common in the facility could cause rapid spread and outbreaks of diseases if interventions to prevent transmission are not put in place. The need to include patients of the facility in surveillance programmes as well as deworming exercises is strongly encouraged (Kwabena et al., 2015). Reports of infection were handed to the management of the hospital for treatment to be given to the patients.

As parasitic infections are observed in the region to provide comprehensive information related to prevalence of intestinal parasites in visceral populations, recommendations from the study will assist government health officials in policy development, interventions such as deworming and health education programs (Nxasana et al., 2013). Public health awareness campaigns will also be recommended as a high rate of reinfection was observed.

In conclusion, the occurrence of intestinal parasitic infection is moderate and comparatively low in the study population
- G.lamblia + E.histolytica

- G.lamblia + Hook worm

E. histolytica + Hook worm

- Glamblia + A.lumbricoides

- G.lamblia + E. histolytica + hookworm

and the Giardia lamblia infections are more common protozoan observed in our study. In most of the cases, intestinal parasitic infestation spreads due to low standards of personal hygiene, poor sanitation, open defecation and also among illiterate population. This study emphasizes the need for health education, good sanitation, personal hygiene, proper cooking of food, safe drinking water and use of foot wears especially amongst the rural population.

\section{References}

Allen, A.V.H., Ridley, D.S. 1970. Further observations on the formol-ether concentration technique for faecal parasites. J. Clin. Pathol., 23: 545-547.

Bandy, D.A., Kan, S.P., and Rose, R. 1988. Age related prevalence intensity and frequency distribution of gastrointestinal helminth infection in urban slum children from Kaulalampur. Malaysia, Trans. $R$. Soc. Trop. Med. Hyg., 82: 289-294.

Ganesh, K.S., Kamal, P.P., Medhavi, S., Santwana, P., Shekhar, C.Y. 2013. The prevalence of intestinal parasitic infestations in a tertiary care hospital - a retrospective study. J. Nobel. Med. Col., 2: 13-17.

Guerrant, R.L., Oria, R., Bushen, O.Y., Patrick, P.D., and Houpt, E. 2005. Global impact of diarrheal diseases that are sampled by travelers: the rest of the hippopotamus. Clin. Infect. Dis., 41: 524530. 
Kang, G., Mathew, M.S., Prasanna, D.S., Jasper, D.D., Minnie, M.M., Mathan, V.I., and Muliyil, J.P. 1998. Prevalence of intestinal parasites in rural Southern Indians. Trop. Med. Int. Hlth., 3: 70-75.

Kwabena, O.D., Yaw, A.K., Simon, K.A., and Patrick, F.A. 2015. Prevalence of intestinal parasites among patients of a Ghanaian psychiatry hospital. BMC. Res. Notes, 8: 651-654.

Nxasana, N., Baba, K., Bhat, V.G., and Vasaikar, S.D. 2013. Prevalence of intestinal parasites in primary school children of Mthatha. Eastern Cape Province, South Africa. Ann. Med. Hlth. Sci. Res., 3: 511-516.

Latha, R., Senthil, K.K., Sasikala, R., Muruganandam, N., and Karthikeyan, R. 2010. Helminthic infections in school children in Puducherry, South India. $J$. Microbiol. Immunol. Infect., 43: 228-232.

Mahesh, B.C., Sonth, S.B., Shivakumar, S., and Chidanand, S.P., 2011. The prevalence of parasitic infections in patients attending tertiary care hospital. Nat. J. Bas. Med. Sci., 2: 31-34.

Manish, K.M., Ajoy, K.V., Gopee, E.M., and Mala, S. 2013. Study of opportunistic intestinal parasitic infections in Human immunodeficiency virus/ Acquired immunodeficiency syndrome patients. $J$. Glob. Infect. Dis., 5: 164-167.

Nkrumah, B., and Nguah, S.B. 2011. Giardia lamblia: a major parasitic cause of childhood diarrhoea in patients attending a district hospital in Ghana. Parasitol. Vect., 3: 163-168.

Parameshwarappa, K.D., Chandrakanth, C., and Sunil, B. 2012. The prevalence of intestinal parasitic infestations and the evaluation of difference concentrations techniques of the stool examination. $J$. Clin. Diagn. Res., 4662: 2392-2397.

Randhir, K., Priyanka, P.B., Tarannum, Y., Aninda, S., and Udayan, G. 2014. Prevalence of intestinal parasitic infections in patients attending a tertiary care hospital in Eastern Bihar. J. Evol. Med. Dent. Sci., 3: 6740-6746.

Saeed, A., Abd, H., and Sandstorm, G. 2015. Microbial aetiology of acute diarrhea in children under five years of age in Khartoum, Sudan. J. Med. Microbiol., 64: 432-437.

Samie, A., Guerrant, R.L., Barrett, L., Bessong, P.O., Igumbor, E.O., and Obi, C.L. 2009. Prevalence of intestinal parasitic and bacterial pathogens in diarrhoeal and non diarroeal human stools form Vhembe district, South Africa. $J$. Hlth. Pop. Nutr., 27: 739-745.

Sethi, S., Sehgal, R., Malla, N., Dudey, M.L., and Mahajan, R.C. 2000. The changing trends of the intestinal parasitic infections in Chandigarh (NG): a hospital based study. Ind. J. Med. Microbiol., 18: 106109.

Srihari, N., Kumudini, T.S., Mariraj, J., and Krishna, S. 2011. Prevalence of intestinal parasitic infection in a tertiary care hospital - a retrospective study. J. Pharm. Biomed. Sci., 12: 1-4.

WHO. 1991. Basic laboratory methods in medical parasitology. Geneva: WHO.

Yam, A.B., Bernard, N., Ali, I., and Samuel, C.K.T. 2012. Gastrointestinal and urinary tract pathogenic infections among HIV seropositive patients at the Komfo Anokye teaching hospital in Ghana. BMC. Res. Notes, 5: 454-458.

\section{How to cite this article:}

Saraswathi, R., J. Lalithambigai, G. Vazhavandal, A. Uma, N. Prabhusaran and Velayutharaj, A. 2016. Prevalence of Intestinal Parasitic Pathogens in Stools from Medical Speciality Units of Tertiary Rural Teaching Hospital, Tamilnadu, India. Int.J.Curr.Microbiol.App.Sci. 5(8): 429-435. doi: http://dx.doi.org/10.20546/ijcmas.2016.508.046 